\title{
Clinical features of viral exanthems
}

Sarajane Ting, Rosemary Nixon

\section{Background \\ Patients with viral exanthems commonly present to the general practitioner. Although it can be challenging to make a specific diagnosis on the basis of the clinical presentation, most viral exanthems can be distinguished initially on the basis of age, distribution and morphology of the rash without requiring investigations.}

\section{Objective}

The aim of this article is to provide an initial guide to the clinical diagnosis of viral exanthems based on age, distribution and morphology of the rash.

\section{Discussion}

Although most viral exanthems can present at any age, it may be helpful to initially consider certain exanthems depending on the age of the patient. Following consideration of differential diagnoses according to age groups, it is proposed that most exanthems can be distinguished by the distribution and morphology of the rash. Other diagnostic considerations include associated symptoms and diagnostic tests if applicable.
PATIENTS WITH VIRAL EXANTHEMS commonly present to the general practitioner (GP) and are usually associated with benign, self-limiting disease. This article outlines the characteristic clinical features seen in specific viral exanthems that may help the clinician to make a more confident diagnosis of a specific viral illness.

Although most viral exanthems can present at any age, some are more common in certain age groups. To assist with a diagnostic framework, it may be helpful for clinicians to approach viral exanthems on the basis of patient age, followed by distribution and morphology of the rash (Table 1). Using this framework, most viral exanthems can be diagnosed clinically with diagnostic investigations used only as a confirmatory tool if needed for atypical or challenging cases. It is important, however, to note that none of the viral exanthems are absolutely limited to a certain age group.

\section{Viral exanthems that more commonly present in children \\ Roseola infantum}

Roseola infantum is caused by human herpesvirus 6 (HHV-6) or 7 (HHV-7) and is spread via respiratory droplets. ${ }^{1,2}$ Roseola primarily affects children aged between six months and two years. Classically, there is a prodrome period of high fever (approximately $40^{\circ} \mathrm{C}$ ) that lasts for 3-5 days. There may be febrile seizures, upper respiratory tract symptoms and lymphadenopathy. As the fever subsides, the exanthem appears, consisting of pink macules and papules starting on the trunk and spreading to the neck, extremities and occasionally the face. The diagnosis usually becomes apparent at this stage. The rash fades in a few days. ${ }^{3}$ Differential diagnoses not to be missed include Kawasaki disease and measles. As opposed to roseola, the maculopapular rash in measles starts on the face and spreads to the trunk and limbs.

\section{Hand, foot and mouth disease}

The cause of hand, foot and mouth disease (HFMD) is an enterovirus infection, usually Coxsackie A16 and Enterovirus 71, and is spread via faecal-oral or oral-oral routes. Following a prodrome of fever, malaise and sore mouth, the mouth lesions precede the exanthem and present as painful ulcerative lesions anywhere in the oral cavity. The exanthem begins as erythematous macules, which progress to form grey elliptical vesicles with an erythematous halo, affecting typically the palms of hands, soles of feet and buttocks. The vesicles crust over and gradually disappear over 7-10 days. ${ }^{4-6}$ However, recent outbreaks of Coxsackie A16 have been associated with atypical presentations including a widespread vesicobullous eruption involving the face, trunk and extremities. Severe blistering with progression to large bullae can occur. If required, the diagnosis can be confirmed by obtaining specimens from 
the oropharynx, skin vesicles, stool or blood for viral culture. Other more serious diagnoses to consider include primary bullous dermatoses, bullous impetigo and eczema herpeticum. ${ }^{4}$ After the acute phase of HFMD, nail changes such as Beau's lines and onychomadesis have been observed, usually within eight weeks after diagnosis. ${ }^{7}$

\section{Laterothoracic exanthem}

Laterothoracic exanthem, also known as asymmetric periflexural exanthem of childhood (APEC), is an uncommon viral exanthem that normally affects females of Caucasian ethnicity between one and five years of age. Laterothoracic exanthem has been associated with Epstein-Barr virus (EBV), adenovirus and parvovirus B19. ${ }^{8-10}$ The eruption begins unilaterally around the axilla or groin, spreads centrifugally, and becomes bilateral in almost all patients (Figure 1). The lesions begin as tiny pink papules often surrounded by a pale halo, before flattening and becoming scaly. At this stage it is often misdiagnosed as tinea or eczema. Older plaques then develop central dusky grey discolouration. There may be associated respiratory and gastrointestinal symptoms. The rash normally resolves spontaneously in about five weeks. ${ }^{11}$

\section{Erythema infectiosum}

Erythema infectiosum, or slapped cheek disease, is caused by parvovirus B19, which is spread typically by respiratory droplets. It is most common in children between four and 10 years of age. Erythema infectiosum presents with a typical prodromal illness followed by a three-stage eruptive phase. The first stage consists of bright red confluent erythema of the cheeks with sparing of the nasal ridge and perioral areas. Approximately 1-4 days after the onset of facial erythema

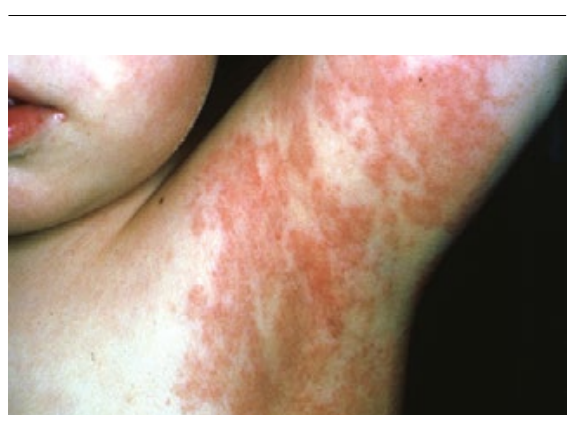

Figure 1. Laterothoracic exanthem spreading centrifugally from the axilla

Table 1. Diagnosis of viral exanthems according to age group, distribution of rash, morphology of rash and diagnostic tests

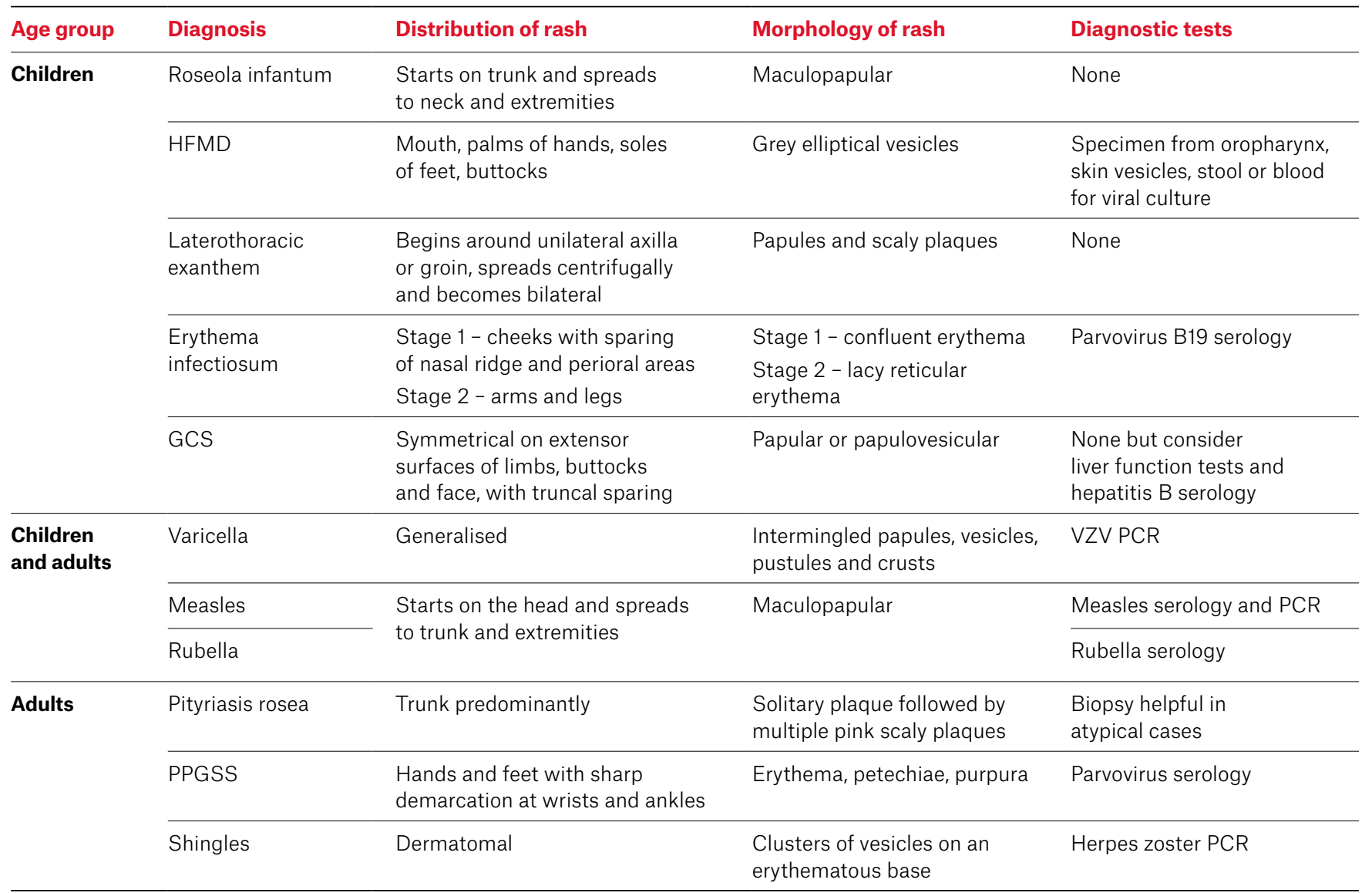

GCS, Gianotti-Crosti syndrome; HFMD, hand, foot and mouth disease; PCR, polymerase chain reaction; PPGSS, papular purpuric gloves and socks syndrome; VZV, varicella zoster virus 
lacy reticular erythema appears on the extremities (Figure 2). Following this, the eruption may fade and then reappear with sunlight exposure, temperature changes or exercise during the next few weeks. ${ }^{12,13}$ Associated arthralgia is more common in adults. If required, the diagnosis can be confirmed by performing parvovirus B19 serology for anti-B19 immunoglobulin (Ig) M. IgG appears one week after and remains positive for life. Importantly, parvovirus B19 infection may cause aplastic crisis in patients with haemolytic anaemia, thalassaemia, sickle cell disease or immunosuppression. ${ }^{12}$ Infection of pregnant women can lead to hydrops fetalis. Pregnant women who have been exposed to parvovirus B19 should have their immune status checked and be referred to an obstetrician if serology indicates an acute infection. ${ }^{14}$

\section{Gianotti-Crosti syndrome}

Gianotti-Crosti syndrome (GCS), or papular acrodermatitis of childhood, has been associated with various viruses including EBV, cytomegalovirus, coxsackie virus, hepatitis A, B and C, HHV-6, respiratory syncytial virus (RSV), parvovirus B19, rotavirus, echovirus, parainfluenza, mumps virus and human immunodeficiency virus (HIV). Reported bacterial causes include Bartonella henselae, beta-haemolytic streptococcus and Mycoplasma pneumoniae..$^{15,16}$ It has also been reported following vaccinations. ${ }^{17,18}$ GCS typically presents in children aged between one and six

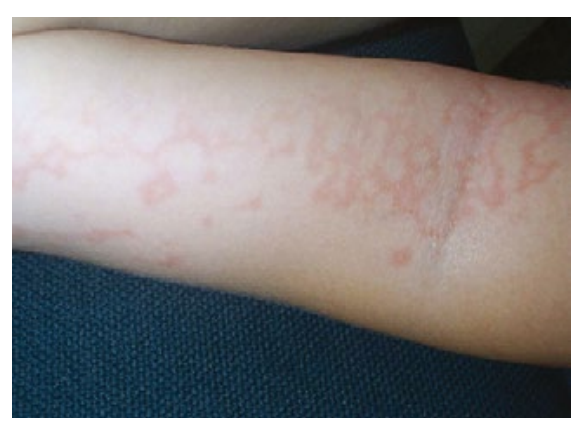

Figure 2. Lacy reticular erythema showing a net-like pattern on the arm of a child with erythema infectiosum years; however, it has also been described in adults. ${ }^{19}$ Most patients present with a prodrome of fever and upper respiratory symptoms. The rash is a symmetrical papular or papulovesicular eruption affecting the extensor surfaces of the upper and lower limbs, buttocks and face (Figure 3). The trunk is typically spared. ${ }^{20}$ It is usually not itchy, so marked pruritus should prompt a search for alternative diagnoses such as scabies or papular urticaria. ${ }^{16}$ Consideration should be given to liver function tests and hepatitis B serology testing, especially in patients who are not immunised. GCS is self-limiting and usually resolves spontaneously within eight weeks. It is important that clinicians are able to recognise this exanthem and make an appropriate diagnosis, as it is immensely reassuring to parents who are often frightened by the extent and appearance of the rash.

\section{Viral exanthems that present at any age \\ Varicella}

Varicella zoster virus (VZV) is one of eight human herpesviruses known to cause two clinically distinct forms of illness: varicella (chickenpox) and herpes zoster (shingles). Primary VZV infection is spread via respiratory droplets and results in chickenpox. ${ }^{21,22}$

The characteristic rash of varicella presents as a pruritic vesicular eruption that occurs on the trunk, limbs and face. There may be few to hundreds of

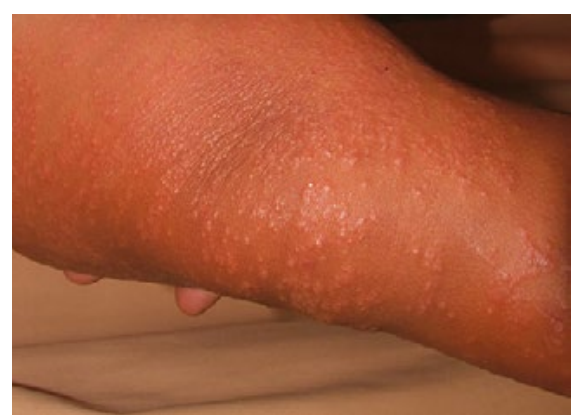

Figure 3. Gianotti-Crosti syndrome presenting as a papulovesicular eruption affecting the extensor surface of the arm lesions. The individual lesion starts as a 2-4 $\mathrm{mm}$ red papule that develops an irregular outline as a thin-walled vesicle appears on the surface, forming the typical appearance of 'dewdrop on a rose petal' (Figure 4). The vesicles become umbilicated and subsequently form crusts. Fresh crops of additional lesions appear, giving the characteristic picture of intermingled papules, vesicles, pustules and crusts. The lesions heal between one and four weeks. There may be associated fever, malaise and fatigue. ${ }^{23,24}$ Adults and immunocompromised patients can experience a more severe illness with extensive haemorrhagic cutaneous lesions and are more likely to develop systemic complications including hepatitis, pneumonia and encephalitis. ${ }^{22}$ The diagnosis can be confirmed by performing VZV polymerase chain reaction (PCR) from a skin swab. Atypical varicella can mimic generalised herpes simplex, impetigo and Stevens-Johnson syndrome (SJS) ${ }^{24}$ Given the risk of congenital varicella syndrome and severe neonatal varicella infection, ${ }^{25}$ special considerations are given to treatment of pregnant mothers who develop varicella during pregnancy.

\section{Measles}

Measles is a highly contagious viral illness spread by respiratory droplets. There is a prodrome of fever, cough, coryza and conjunctivitis. Patients with measles generally look unwell and feel miserable. Just prior to the onset of the exanthem,

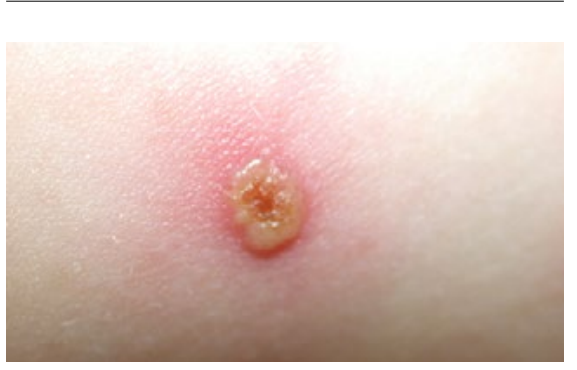

Figure 4. 'Dewdrop on a rose petal' appearance classically seen in varicella, formed by a vesicle that appears on the surface of a pink papule. The vesicle subsequently becomes umbilicated and forms a crust on its surface. 
grey-white papules develop on the buccal mucosa (Figure 5). These so-called Koplik spots are highly predictive for measles. ${ }^{26}$ The exanthem consists of red macules and papules that begin on the head and spread in a cephalocaudal manner. The rash begins to fade on the fifth day, in the order of appearance. Differential diagnoses include scarlet fever, Kawasaki disease, Staphylococcal scalded skin syndrome, toxic shock syndrome and SJS. The diagnosis is confirmed by measles serology as well as sending a nasopharyngeal swab for measles PCR. Complications of measles include otitis media, pneumonia, myocarditis and subacute sclerosing panencephalitis (SSPE), which begins years after the initial infection. ${ }^{27-29}$

\section{Rubella}

In contrast to measles, infection with rubella usually results in a mild or subclinical infection, especially in children. The eruption presents as a pink maculopapular rash that begins on the face and spreads to the trunk and extremities over 24 hours. There may be erythematous papules on the soft palate (Forchheimer spots). The exanthem subsides in 2-3 days in the order in which it appeared. Tender lymphadenopathy is prominent. Arthritis is more common in adults. The diagnosis is confirmed by rubella serology. ${ }^{30}$ Rubella exposure during pregnancy can lead to intrauterine infection and subsequent congenital rubella syndrome. ${ }^{31}$ Therefore every effort should be made to ensure

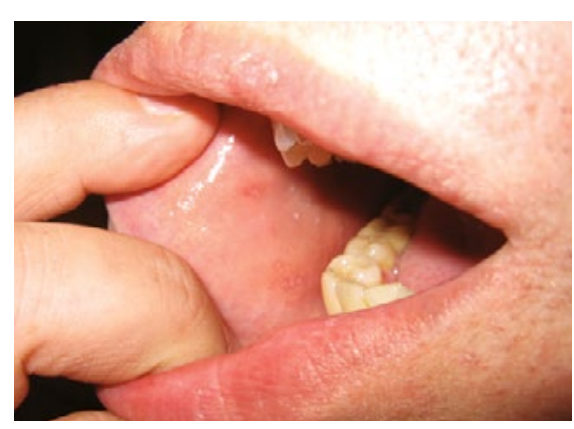

Figure 5. Grey-white papules on the buccal mucosa (Koplik spots) seen in measles women of childbearing age have adequate immunity against rubella.

\section{Viral exanthems that more commonly present in adults}

\section{Pityriasis rosea}

Pityriasis rosea is a common, self-limiting condition that has also been associated with HHV-6 and HHV-7. It primarily affects young adults. Pityriasis rosea typically begins with a 'herald patch': an asymptomatic well-demarcated pink scaly plaque usually on the trunk or less commonly on the limbs (Figure 6). The herald patch may be mistaken for tinea. Over the next days to weeks, a secondary eruption occurs, which consists of scaly pink plaques following the classic fir-tree distribution on the trunk. The plaques exhibit a fine collarette of scale at the edges. Itch, if it occurs, is usually mild. Atypical pityriasis rosea may present with vesicular, purpuric, urticarial or haemorrhagic lesions. An inverse form of pityriasis rosea affects flexural surfaces such as the axillae and groin. ${ }^{32}$ In atypical pityriasis rosea, a biopsy may be useful to confirm the diagnosis. The eruption normally subsides within 12 weeks but can occasionally persist for more than five months. ${ }^{32,33}$ Differential diagnoses include guttate psoriasis, pityriasiform medication eruption and secondary syphilis, especially if there is palmoplantar involvement in sexually active patients. Medications that cause a pityriasiform medication eruption include terbinafine,

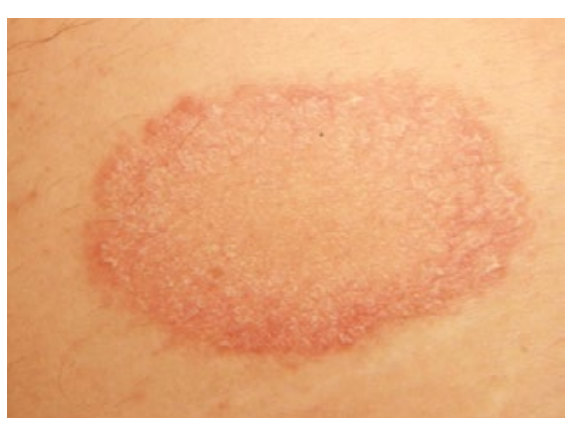

Figure 6. Herald patch of pityriasis rosea a well-demarcated scaly plaque that can be mistaken for tinea metronidazole, clonidine, captopril, isotretinoin, omeprazole and nonsteroidal anti-inflammatory drugs (NSAIDs). ${ }^{32}$

\section{Papular purpuric gloves and socks syndrome}

Besides erythema infectiosum, a rarer manifestation of parvovirus B19 is papular purpuric gloves and socks syndrome (PPGSS). Other potential causes include EBV, hepatitis B virus and HHV-6. This exanthem is most common in young adults. As its name suggests, the exanthem presents as erythema, oedema, petechiae and purpura of both hands and feet involving both the dorsal and palmoplantar surfaces, with a sharp demarcation at the wrists and ankles. Patients may complain of burning and pruritus. Some patients may also have an accompanying enanthem, characterised by oral erosions, vesicles and petechiae of the hard palate and tongue. This condition resolves spontaneously over one to two weeks. Unlike erythema infectiosum, patients are infectious during the appearance of the skin eruption. ${ }^{12,34}$

\section{Shingles}

Following primary varicella infection, VZV remains latent in neurons of the dorsal root ganglia, cranial nerve ganglia and autonomic ganglia. Triggers for reactivation of VZV include age, recent physical trauma, fatigue, emotional stress and radiation therapy, leading to shingles. ${ }^{21,22}$

Classically, patients experience tingling and burning pain localised to the dermatome, which precedes the eruption by 4-5 days. There may be fever, malaise and lymphadenopathy. The eruption presents as vesicles arising in clusters on an erythematous base (Figure 7), before forming crusts and subsequently healing in 2-3 weeks. ${ }^{35}$ Occasionally, distant lesions are seen as a result of involvement of a dermatome covering distant sites such as L5, where lesions can present in the lower back and distal to the knee; or, very rarely, due to herpes zoster duplex, where two different non-contiguous dermatomes are affected, causing even bilateral lesions that cross the midline. ${ }^{36,37}$ If required, the diagnosis is confirmed by herpes zoster PCR from a skin swab. Post-herpetic neuralgia is the most common debilitating 


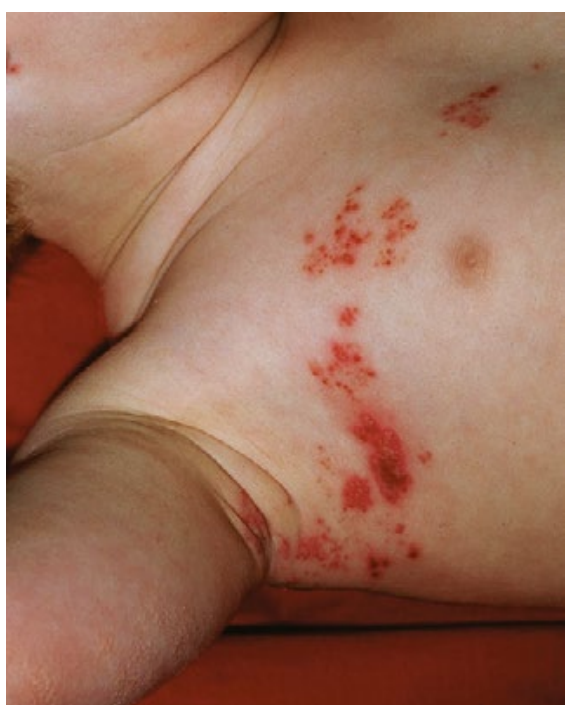

Figure 7. Clusters of vesicles on an erythematous base localised to a dermatome in shingles

complication of herpes zoster presenting as burning pain in the area of the healed rash, which can last for months to years and cause severe distress. ${ }^{38}$ Zoster ophthalmicus, which merits urgent assessment and referral, occurs when the first branch of the trigeminal nerve is affected, causing ocular complications such as keratitis, uveitis and retinal necrosis, which can lead to monocular blindness. ${ }^{35,36}$ A clue to this diagnosis is Hutchinson's sign, where vesicles are seen on the tip or the side of the nose. ${ }^{36}$

\section{Non-specific viral exanthem}

Despite the distinct features of viral exanthems described above, some viruses cause a non-specific exanthem usually in association with a respiratory illness. These viruses include adenovirus, RSV, parainfluenza and influenza A/B. This non-specific exanthem is more common in children and usually presents as a diffuse maculopapular rash that resolves within five days. ${ }^{39}$

\section{Conclusion}

Many viral illnesses can present with a rash. It may be helpful for clinicians to approach the diagnosis of viral exanthems initially using age, distribution and morphology of rash. If required, diagnostic tests can be performed. Most viral exanthems are self-limiting; however, clinicians should consider serious diagnoses not to be missed and potential complications.

\section{Authors}

Sarajane Ting MBBS (Hons), BMedSc, FRACGP, DCH, PDipDerm, General Practitioner, Tas Rosemary Nixon AM, BSc (Hons), MBBS, MPH, FACD, FAFOEM, Consultant Dermatologist and Occupational Physician; Adjunct Clinical Associate Professor, Monash University, Vic; Honorary Associate Professor, The University of Melbourne, Vic; Director, Occupational Dermatology Research and Education Centre, Vic

Competing interests: None.

Funding: None.

Provenance and peer review: Not commissioned, externally peer reviewed.

Correspondence to:

sjaneting@gmail.com

\section{Acknowledgements}

The authors would like to acknowledge Associate Professor Amanda Oakley for providing the images in this article.

\section{References}

1. Yamanishi K, Okuno T, Shiraki K, et al. Identification of human herpesvirus- 6 as a causal agent for exanthem subitum. Lancet 1988;1(8594):1065-67. doi: 10.1016/s01406736(88)91893-4

2. Tanaka K, Kondo T, Torigoe S, Okada S, Mukai T, Yamanishi K. Human herpesvirus 7: Another causal agent for roseola (exanthem subitum) J Pediatr 1994;125(1):1-5. doi: 10.1016/s00223476(94)70113-x.

3. Stoeckle MY. The spectrum of human herpesvirus 6 infection: From roseola infantum to adult disease. Annu Rev Med 2000;51:423-30. doi: 10.1146/annurev.med.51.1.423.

4. Ventarola D, Bordone L, Silverberg N. Update on hand-foot-and-mouth disease. Clin Dermatol 2015;33(3):340-46. doi: 10.1016/j. clindermatol.2014.12.011.

5. Sawyer $\mathrm{MH}$. Enterovirus infections: Diagnosis and treatment. Semin Pediatr Infect Dis 2002;13(1):40-47. doi: 10.1053/spid.2002.29756.

6. Zaoutis T, Klein JD. Enterovirus infections. Pediatr Rev 1998;19(6):183-91. doi: 10.1542/pir.19-6-183.

7. Giordano $M C L$, de la Fuente $A L$, Lorca MBJ, Kramer DH. Onicomadesis secundaria a enfermedad pie-mano-boca: una manifestación frecuente y motivo de preocupación de los padres [Onychomadesis secondary to handfoot-mouth disease: A frequent manifestation and cause of concern for parents]. Rev Chil Pediatr 2018;89(3):380-83. doi: 10.4067/S037041062018005000203

8. Niedermeier A, Pfützner W, Ruzicka T, Thomas P Happle R. Superimposed lateralized exanthem of childhood: Report of a case related to adenovirus infection. Clin Exp Dermatol 2014;39(3):351-53. doi: 10.1111/ced.12311.
9. Duarte AF, Cruz MJ, Baudrier T, Mota A, Azevedo F. Unilateral laterothoracic exanthem and primary Epstein-Barr virus infection: Case report. Pediatr Infect Dis J 2009;28(6):549-50 doi: 10.1097/INF.0b013e318193eca7.

10. Chuh A. Asymmetric periflexural/unilateral laterothoracic exanthem related to parvovirus B19 infection: An adult carrier of B-globin thalassaemia gene mutation in Hong Kong. Australas J Dermatol 2016;57(4):e141-43. doi: 10.1111/ajd.12403.

11. McCuaig CC, Russo P, Powell J, Pedneault L, Lebel P, Marcoux D. Unilateral laterothoracic exanthem. A clinicopathologic study of forty-eight patients. J Am Acad Dermatol 1996;34(6):979-84. doi: 10.1016/s0190-9622(96)90275-3.

12. Vafaie J, Schwartz RA. Parvovirus B19 infections. Int J Dermatol 2004;43(10):747-49. doi: 10.1111/j.1365-4632.2004.02413.x.

13. Vafaie J, Schwartz RA. Erythema infectiosum. J Cutan Med Surg 2005;9(4):159-61. doi: 10.1007/ s10227-005-0101-8.

14. Miller E, Fairley CK, Cohen BJ, Seng C. Immediate and long term outcome of human parvovirus B19 infection in pregnancy. Br J Obstet Gynaecol 1998;105(2):174-78. doi: 10.1111/j.1471-0528.1998. tb10048.x.

15. Taïeb A, Plantin P, Du Pasquier P, Guillet G, Maleville J. Gianotti-Crosti syndrome: A study of 26 cases. Br J Dermatol 1986;115(1):49-59. doi: 10.1111/j.1365-2133.1986.tb06219.x.

16. Fastenberg M, Morrell DS. Acral papules: GianottiCrosti syndrome. Pediatr Ann 2007;36(12):800-04 doi: 10.3928/0090-4481-20071201-10.

17. Karakaş M, Durdu M, Tuncer I, Cevlik F. GianottiCrosti syndrome in a child following hepatitis $B$ virus vaccination. J Dermatol 2007;34(2):117-20. doi: 10.1111/j.1346-8138.2006.00229.x.

18. Kroeskop A, Lewis AB, Barril FA, Baribault KE. Gianotti-Crosti syndrome after H1N1-influenza vaccine. Pediatr Dermatol 2011;28(5):595-96. doi: 10.1111/j.1525-1470.2011.01402.x.

19. Ting PT, Barankin B, Dytoc MT. Gianotti-Crosti syndrome in two adult patients. J Cutan Med Surg 2008;12(3):121-25. doi: 10.2310/7750.2007.00044.

20. Chuh AA. Diagnostic criteria for Gianotti-Crosti syndrome: A prospective case-control study for validity assessment. Cutis 2001;68(3):207-13.

21. Gershon AA, Breuer J, Cohen Jl, et al. Varicella zoster virus infection. Nat Rev Dis Primers 2015;1:15016. doi: 10.1038/nrdp.2015.16.

22. Kennedy PGE, Gershon AA. Clinical features of varicella-zoster virus infection. Viruses 2018;10(11):609. doi: 10.3390/v10110609.

23. Hambleton S. Chickenpox. Curr Opin Infect Dis 2005;18(3):235-40. doi: 10.1097/01. qco.0000168384.31766.89.

24. Vázquez M. Varicella infections and varicella vaccine in the 21 st century. Pediatr Infect Dis J 2004;23(9):871-72. doi: 10.1097/01. inf.0000140786.15816.38.

25. Forrest J, Mego S, Burgess M. Congenital and neonatal varicella in Australia. J Paediatr Child Health 2000;36(2):108-13. doi: 10.1046/j.14401754.2000.00474.x

26. Zenner D, Nacul L. Predictive power of Koplik's spots for the diagnosis of measles. J Infect Dev Ctries 2012;6(3):271-75. doi: 10.3855/jidc.1756.

27. Elliman D, Sengupta N. Measles. Curr Opin Infect Dis 2005;18(3):229-34.

28. Hogan PA. Viral exanthems in childhood. Australas J Dermatol 1996;37 Suppl 1:S14-16. doi: 10.1111/ j.1440-0960.1996.tb01071.x. 
29. Rota PA, Moss WJ, Takeda M, de Swart RL,

Thompson KM, Goodson JL. Measles. Nat Rev Dis

Primers 2016;2:16049. doi: 10.1038/nrdp.2016.49.

30. Rosa C. Rubella and rubeola. Semin Perinatol 1998;22(4):318-22. doi: 10.1016/s01460005(98)80020-7.

31. Fine JD, Arndt KA. The TORCH syndrome: A clinical review. J Am Acad Dermatol 1985;12(4):697-706. doi: 10.1016/s01909622(85)70095-3.

32. Drago F, Ciccarese G, Rebora A, Broccolo F, Parodi A. Pityriasis rosea: A comprehensive classification. Dermatology 2016;232(4):431-37.

33. Hartley AH. Pityriasis rosea. Pediatr Rev 1999;20(8):266-69, quiz 270. doi: 10.1542/pir.208-266.

34. Smith PT, Landry ML, Carey H, Krasnoff J, Cooney E. Papular-purpuric gloves and socks syndrome associated with acute parvovirus B19 infection: Case report and review. Clin Infect Dis 1998;27(1):164-68. doi: 10.1086/514629.

35. Dayan RR, Peleg R. Herpes zoster Typical and atypical presentations. Postgrad Med 2017;129(6):567-71. doi: 10.1080/00325481.2017.1335574.

36. Wollina U. Variations in herpes zoster manifestation. Indian J Med Res 2017;145(3):294-98. doi: 10.4103/ ijmr.IJMR_1622_16.

37. Vijay A, Dalela G. Herpes zoster duplex bilateralis in immuno-competent patients: Report of two cases. J Clin Diagn Res 2015;9(12):WR01-03. doi: 10.7860/JCDR/2015/15728.6957.

38. Gross G, Doerr HW. Herpes zoster guidelines of the German Dermatological Society. J Clin Virol 2003;27(3):308-09. doi: 10.1016/s13866532(03)00125-2.

39. Drago F, Ciccarese G, Gasparini G, et al. Contemporary infectious exanthems: An update. Future Microbiol 2017;12:171-93. doi: 10.2217/fmb2016-0147. 